\title{
As representações sociais de funcionários de uma Instituição de Longa Permanência sobre violência no interior de Minas Gerais
}

Alcione Tavora Kullok ${ }^{1}$

Ivana de Cássia Baptista dos Santos²

\section{Introdução}

Este artigo é o resultado do estudo que se propôs a identificar o conhecimento prévio dos funcionários de uma Instituição de Longa Permanência de Idosos (ILPIs) sobre tipos de maus-tratos, como um dos itens problematizadores para a preparação do curso de capacitação da equipe multidisciplinar: "Envelhecimento Institucionalizado e a Re-apropriação da Identidade", solicitado pela instituição em conformidade com o Art. 18 do Estatuto do Idoso, que prevê o treinamento e a capacitação dos profissionais, assim como orientações a cuidadores, familiares e grupos de autoajuda. O curso objetivou ainda, preparar todos os funcionários da Instituição para assistir a esses idosos com um novo olhar e uma nova ressignificação nas práticas do cuidar, considerando as ressonâncias do envelhecimento biológico, das patologias que podem acompanhá-lo e das respostas sociais que determinam atitudes de rejeição ou acolhimento.

Estima-se que 1\% dos idosos brasileiros esteja institucionalizado, com diversos níveis de dependência (Chaimowicz, Greco, 1999). Segundo a Pesquisa Nacional por Amostra de Domicílios (PNAD) de 2001 (IBGE, 2005), existem um e meio milhão de idosos dependentes no Brasil. Neste cenário, no qual se acumula o envelhecimento com doenças cronicodegenerativas, e na dependência de uma ou mais pessoas que supram as suas incapacidades para a realização das atividades de vida diária, também se concentra o envelhecimento saudável. O Brasil está passando por um processo de envelhecimento populacional rápido e intenso, havendo a expectativa de alcançar 15\% em 2020 (Camarano, 1997).

Apesar dos avanços investigativos na área da geriatria e gerontologia da última década, no Brasil os estudos acerca das Instituições de Longa Permanência ainda são incipientes; e, ainda hoje, depara-se com sérios problemas relacionados à qualidade do cuidado, que só vêm à tona nos escândalos dos noticiários, como o caso de elevado número de mortes de idosos na Clinica Santa Genoveva, Rio de Janeiro, gerando preocupações, e alvo de investigação de pesquisadores da área de saúde (Guerra et al., 2000). Tal situação demonstra a necessidade urgente de investigações sobre as condições de vida dos idosos institucionalizados no nosso país. Recentes estudos (Born, Boechat, 2006; Kullok et al., 2006; Machado, Queiroz, 2006; Papaleo Netto, 2006) demonstram a existência de sérios

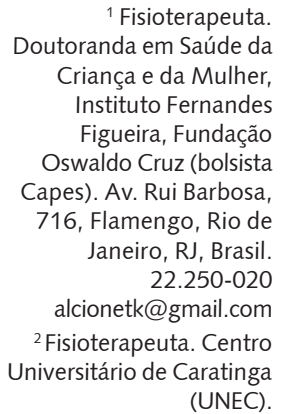
(UNEC). 
problemas em idosos com dependência, tais como: úlceras de pressão, desnutrição, incontinência urinária, dor, negligência e maus-tratos. Machado e Queiroz (2006) sugerem que mulheres idosas, em situação de comprometimento cognitivo, físico e mental são vítimas em potencial. Idosos com dependência, aos cuidados dos familiares, podem sofrer agressão verbal e até física, deixando-os muito culpados. As dívidas de reciprocidade despertam sentimentos ambíguos, que podem conduzir à agressão. Essa responsabilidade tem um embasamento nas normas de "obrigação filial" e "obrigação familiar", resultantes de códigos morais e religiosos - tais como no Judaísmo, Cristianismo, Confucionismo, Budismo, dentre outros (Aboderin, 2004; Kemp, 2003). As trocas intergeracionais continuam a ser um aspecto primordial das relações familiares nas sociedades modernas e pósmodernas. O conteúdo e a intensidade, o sentido dos fluxos são alguns dos aspectos a se considerarem na reconstituição das relações entre as gerações. De modo geral, as trocas concretizam-se em torno do domínio afetivo, da ajuda doméstica e financeira, da guarda das crianças e dos cuidados gerais em caso de doença ou incapacidade. "Dá-se" e "recebe-se" ("Dom" e "contra Dom") tempo de convívio e atenção, serviços de várias ordens e, talvez, o que mais facilmente se consegue contabilizar: ajudas financeiras e presentes (Brandão, 1999; Gil, 1999; Attias, Donfut, 1995).

A Organização Pan-Americana de Saúde (OPAS, 1996) declara que a violência, pelo número de vítimas e a magnitude de sequelas que produz, adquiriu um caráter endêmico e se converteu num problema de saúde pública. Outro marco legal da maior importância foi a inclusão dos maus-tratos a idosos no documento do Plano de Ação da $2^{a}$ Assembléia Mundial do Envelhecimento, realizada em Madrid em 2002 (art. 98 e 100).

No Brasil, somente a partir da década de 1980 é que essa questão começou a despertar o interesse na comunidade científica. Esse crescimento ocorreu, sobretudo, devido a dois fatores: conscientização dos valores da vida e dos direitos de cidadania, e mudanças no perfil de morbimortalidade no mundo e no país. Dentro do estudo da violência, os maus-tratos contra os idosos foram os últimos a serem contemplados como fenômeno político e como questão de saúde pública, após os estudos sobre a violência contra a mulher e a violência infantil (Machado, Queiroz, 2006).

Nesse sentido, optou-se por utilizar o consenso internacional de todos os países participantes da Rede Internacional de Prevenção contra Maus-Tratos em Idosos, e endossada pela Organização Mundial de Saúde (OMS, 2002) e pela portaria do Ministério da Saúde (MS) do Brasil de 2001. A prerrogativa dessa opção é preservar uma homogeneidade de conceitos. São definidos sete tipos de violências: abuso físico ou maus-tratos físicos concerne ao uso de força física, potencialmente produtor de uma injúria, ferida, dor ou incapacidade; abuso ou maus-tratos psicológicos envolve agressões verbais ou gestuais com o objetivo de aterrorizar, rejeitar, humilhar a vítima, restringindo sua liberdade ou, ainda, isolá-la do convívio social; a negligência é a recusa, omissão ou fracasso por parte do responsável no cuidado com a vítima, porquanto a autonegligência é conceituada como conduta de pessoa idosa que ameaça sua própria saúde ou segurança, com a recusa ou o fracasso de prover a si mesma um cuidado adequado; o abandono é descrito como ausência ou deserção, por parte do responsável, dos cuidados necessários às vítimas, às quais caberia prover custódia física e cuidado; abuso financeiro aos idosos ocorre quando há exploração imprópria ou ilegal e/ou uso não consentido de seus recursos financeiros; e o abuso sexual, que é o ato ou jogo sexual, em uma relação hétero ou homossexual, destinado a estimular a vítima ou utilizá-la para obter excitação sexual e práticas erótico-sexuais impostas por meio de aliciamento, violência física ou ameaças.

Todas essas formas de violência interpessoal, comunitária e estrutural, são aqui entendidas como expressões de ausência dos direitos da pessoa idosa.

Estimativas sobre abuso em idosos são difíceis de obter-se devido ao caráter frequentemente velado do problema. Essa subnotificação associa-se, muitas vezes, à solidão, ao isolamento e à tendência dos indivíduos idosos a não relatarem suas adversidades (Kosberg, 1988).

Há poucas evidências sobre como, efetivamente, suspeitar ou reconhecer a presença de abuso, e são poucos os profissionais de saúde que ativamente rastreiam pacientes que não possuam alguma lesão aparente (Rathbone, Voyles, 1982).

Muitas vezes, os atores envolvidos na trama da violência estão ligados por laços consanguíneos, que acabam mascarando ou impedindo a detecção de todos os elementos que a compõem. Minayo e Souza 
(2005) citam estudo da OMS/IPEA, Missing Voices, no qual se destaca o fato de os idosos dificilmente falarem da violência que sofrem. Mas e os idosos dependentes, acamados, afásicos, que vivem em ILPIs, cuidados por pessoas sem vínculos de afeto consanguíneo, os quais, muitas vezes, sofrem maustratos perpetrados por esses próprios cuidadores, a quem devem se dirigir? Denunciar? Não serão eles os missing voices?

Um dado importante é o fato de não existir um maior conhecimento da realidade dos maus-tratos em idosos institucionalizados em nosso país (Machado, Queiroz, 2006). Neste texto o verbo institucionalizar é empregado no sentido de se colocar ou confiar alguém aos cuidados de uma instituição especializada (Ferreira, 1999; Michaelis, 1998). Este modelo apareceu na Europa no século $\mathrm{XVI}$, destinado a albergar loucos, vagabundos, foras-da-lei e idosos. Considerando os estereótipos negativos associados à pobreza, abandono ou rejeição familiar, uma forma utilizada para suavizar esses termos, tanto em instituições públicas como privadas, é a de substituí-los por outros, como: Lar dos Idosos, Casa de Repouso, Clínica Geriátrica, Casa da Vovó, Pousada para idosos, entre outras.

As taxas atuais de uso das instituições oscilam entre 4\% e 7\% em países como Canadá $(6,8 \%)$, Estados Unidos (4\%), Israel (4,4\%), África do Sul (4,5\%). Na China a expectativa de assistência institucional para o idoso está se convertendo em norma. Em Taiwan (China) a assistência institucional aos idosos superou rapidamente a atenção familiar (Lemos, Medeiros, 2006).

Na América Latina as taxas variam entre $1 \%$ e $4 \%$. No Brasil, estima-se em $1 \%$, segundo o Ministério da Saúde. O cuidado das pessoas idosas em instituições especializadas, nos países da América Latina, tem sido considerado, pelas famílias, como uma opção possível. Os asilos patrocinados pelo Estado, enormes instituições semelhantes aos antigos asilos de pobres da Inglaterra, transformaram-se em estabelecimentos menores, com pessoal profissional multidisciplinar.

No Brasil, as modalidades de proteção e atendimento aos idosos estão a cargo de instituições públicas e privadas. O atendimento prestado pelas instituições de longa permanência volta-se, prioritariamente, para a parcela mais carente da população idosa, e está presente na grande maioria de nossas comunidades, por meio dos tradicionais asilos e vilas vicentinas (Siqueira, 2007; Lemos, Medeiros, 2006). Embora seja indiscutível a necessidade de funcionários qualificados para assegurar o padrão de qualidade das ILPIs, muitas, sobretudo aquelas de natureza beneficente, lutam, permanentemente, com limitações de ordem financeira (Born, 2007).

Um dos maiores problemas encontrados para a conciliação entre o ideal e o mínimo indispensável para se garantir atendimento satisfatório aos idosos, reside na grande dificuldade em se definir um padrão de funcionamento.

Em 2005, foi decretado o Regulamento Técnico para o funcionamento das Instituições de Longa Permanência para Idosos, buscando definir os critérios mínimos para o funcionamento e avaliação, bem como mecanismos de monitoramento destas Instituições; a prevenção e redução dos riscos à saúde aos quais ficam expostos os idosos residentes em instituições de Longa Permanência, e garantir a essa população idosa os direitos assegurados na legislação em vigor.

Nesse contexto de idosos carentes, residentes em uma Instituição de Longa Permanência para Idosos (ILPI), filantrópica, e que está a cargo de uma comunidade religiosa, é que se encontra o grupo pesquisado.

\section{Material e método}

O presente estudo foi realizado numa ILPI, em um município de Minas Gerais, que apresenta as seguintes características: uma área externa, referente a uma vila destinada aos idosos independentes, e uma área interna subdividida em duas alas distintas (área feminina, com quarenta idosas, e área masculina, com trinta idosos). Destes, 27 idosos (dez homens e 17 mulheres) são cadeirantes, e os demais apresentam dependência parcial para a realização das atividades de vida diária (AVD's).

Foram obedecidas, nesta pesquisa, as orientações contidas na Resolução 196/96 do Ministério da Saúde, tanto nos aspectos éticos com a Instituição que autorizou a realização da pesquisa, quanto com os sujeitos que cederam as entrevistas após leitura e assinatura do Termo de Consentimento Livre e 
Esclarecido. Aos participantes do estudo foram informados os objetivos da pesquisa e as possíveis utilizações das informações obtidas para estudos posteriores, adotando-se o anonimato dos informantes.

Os participantes foram: funcionários da lavanderia, cuidadores de idosos, técnicos de enfermagem, encarregados da limpeza, cozinheiras, e a secretária, o presidente e o vice-presidente da Instituição, somando-se, ao todo, 13 entrevistados.

Todas as entrevistas foram agendadas, sendo necessários cerca de trinta dias para sua conclusão. Elas foram gravadas em fita cassete e, posteriormente, transcritas e revisadas. Foram realizadas por duas pesquisadoras com experiência no atendimento a idosos, e aplicadas na Instituição estudada.

A idade média simples foi 41,6 anos, com nível de escolaridade entre cinco a oito anos de estudo porém, uma das participantes era analfabeta, sabendo somente escrever seu nome porque seu filho a havia ensinado. A média do tempo de trabalho foi de dez anos e oito meses.

Realizou-se estudo de abordagem qualitativa, de cunho exploratório-descritivo para investigar as representações sociais da violência entre os funcionários e diretoria na instituição de Longa Permanência desse Município. A análise dos dados, oriundos da transcrição das entrevistas e das comunicações das ILPIs, foi processada por meio da análise de conteúdo (Moraes, 1994). As unidades de significado, identificadas no processo de análise de conteúdo, foram codificadas pelos pesquisadores - utilizou-se a letra $\mathrm{D}$ para dirigentes e $\mathrm{F}$ para os funcionários -, porém optou-se por não se explicitar a natureza do cargo dos funcionários para manter o anonimato dos entrevistados.

O referencial metodológico de natureza qualitativa utilizado foi o das representações sociais enquanto procedimento metodológico. As representações sociais: " [...] são conhecimentos sociais que situam o indivíduo no mundo e, situando-o, define sua identidade social - o seu modo de ser particular, produto de seu ser social [...]" (Spink, 1995, p.8).

Com base no pressuposto segundo o qual o indivíduo é concebido como um todo - em que o singular e a totalidade social são indissociáveis - e o sujeito, ao elaborar e comunicar suas representações, recorre a significados socialmente constituídos e de sentidos pessoais decorrentes de suas experiências cognitivas e afetivas, Lane e Sawaia (1995) ressaltam a importância do conceito de representação social como dado empírico do qual se parte para uma análise dialética que permite conhecer concretamente a consciência, a atividade e a identidade de sujeitos situados social e historicamente.

Portanto, o mundo da vida cotidiana é tecido por significados, construídos pelas ações humanas e passíveis de interpretações. Não existe uma realidade a priori, mas toda realidade é uma representação, reapropriada e reconstruída pelos indivíduos, integrando o seu sistema de valores e condicionada à história e às relações sociais (Sawaia, 1994).

A fim de aprofundar a investigação sobre as percepções, crenças, motivações e atitudes dos funcionários e diretores dessas Instituições, foram realizadas entrevistas semiestruturadas individuais para se evitarem situações de constrangimento, vergonha ou, mesmo, influências entre as respostas.

A técnica da entrevista é considerada, por Minayo, Assis e Souza (2005), como uma conversa com finalidade. Na modalidade que foi utilizada neste estudo, o entrevistado teve a possibilidade de discorrer sobre o tema sem se prender às perguntas que serviram como guia para o entrevistador.

Foi utilizado, ainda, um diário de campo, no qual foram registradas as observações feitas em todos os contatos com os funcionários, pontuando-se eventuais contradições. Na análise, os dados foram ordenados em unidades básicas descritivas, que se relacionavam entre si de forma a ressaltar padrões, semelhanças e diferenças, repetições, temas e conceitos.

$\mathrm{Na}$ interpretação, buscamos atribuir significados à análise, explicando os padrões encontrados e identificando relacionamentos entre as dimensões descritivas, sob a luz de um exame detalhado da literatura que traz reflexões acerca dos aspectos encontrados e suas consequências sobre os maus tratos em idosos. 


\section{Resultados e discussão}

Quando questionados sobre "o que significa violência para você?" os pesquisadores puderam sentir que, no grupo pesquisado, entre homens e mulheres, a primeira pergunta era de tal forma impactante que momentos de silêncio se repetiam e as respostas eram praticamente as mesmas: "Falar assim é difícil"; "na hora assim... é difícil; falar assim é... muito difícil"; "Como que falo... some da minha mente agora..." A percepção dos pesquisadores quanto a esse grupo é a de que, para eles, conceituar violência foi difícil, mas ressignificá-la, no pólo representacional e vivencial, se tornou mais fácil ao utilizarem a seguinte indagação: quando se fala em violência, o que lhe vem à cabeça, na sua imaginação? Seguem respostas dos participantes: "Eu acho que tudo que agride o físico, o ser humano" "Agressão, violência física, bater"; "Pessoas ruins, pessoas boas não faz violência"; " Uma das piores coisas que existe no mundo. De todas as coisas ruins, a violência está entre as piores"; "Tem todo tipo de violência"; "Falta de amor"; "É gritar com o outro, é empurrar"; "As mulheres, os filhos serem espancados"; "Maltratar os outros"; "Pessoa agredir a gente, os meninos da gente, judiá, pegar menininha novinha"; "Bater nos outros, fazer maldade, judiar da pessoa"

Em quase todas as entrevistas, ao associar a palavra violência, o imaginário pessoal estava povoado com a violência física ou abuso físico; e estes termos eram relacionados aos ciclos da vida e gênero: crianças, adolescentes, mulheres e homens, porém, em nenhum momento, foram citados os idosos. Fato este que nos chamou bastante atenção, visto que os entrevistados tinham, em média, 11 anos de trabalho na Instituição. Apenas um entrevistado mencionou a violência contra os idosos, porém já havia passado por um curso de qualificação para cuidadores, e se referia aos maus-tratos psicológicos:

"Violência principalmente no setor para nós que trabalha no setor é a violência contra os idoso, a gente tem que tomar cuidado até no modo de dirigir um idoso porque pela 'lei do idoso' até um tom mais alto a gente ta cometendo uma violência contra o idoso"; "Violência verbal, 'xingar' uma pessoa, ou dar um tapa".

Outro tipo da violência muito citada foi o abuso ou maustratos psicológicos que envolvem agressões verbais ou gestuais com o objetivo de aterrorizar, rejeitar, humilhar a vítima, restringindo sua liberdade ou, ainda, isolá-la do convívio social. Mas aqui nesses depoimentos ainda percebe-se que as falas encontram-se relacionadas às marcas vividas e revividas de um passado violento pessoal: "Um tom mais alto é uma violência"; "Violência é gritar com a gente, não saber falar com a gente, chamar atenção na frente dos outros. Pra mim, se eu fizer alguma coisa errada, pode me chamar num canto e falar. Se gritar comigo, acabou. Tem que saber falar positivo, com educação, detesto grito, pra mim é o mesmo que me bater, ou até pior"; "Gritar".

O falar mais alto, os gritos, são aspectos comportamentais de violência interpessoal que acontecem nos espaços públicos, como escolas, empresas, entre outros; e, sobretudo no espaço privado da família, eles acontecem de forma generalizada e banalizada, porém causando consequências nefastas nas pessoas a longo e/ou curto prazo.

Para Freire (1996) e Streck (1999), esses comportamentos acontecem devido ao individualismo e à falta do diálogo; e só a partir da construção de uma sociedade do eu com nós, com olhar para o futuro, e um processo de educação voltado para o sentido da cidadania, com uma inclusão participativa, e justiça para todos, poderá se falar em um mundo com paz. A fala de Paulo Freire na Unesco, em Paris, em 1986, quando recebeu o prêmio "Educador para a paz", é extremamente ilustrativa:

[...] A paz se cria, se constrói na e pela superação de realidades sociais perversas. A paz se cria, se constrói na construção incessante da justiça social. Por isso, não creio em nenhum esforço chamado de educação para a paz que, em lugar de desvelar o mundo das injustiças o torna opaco e tentam miopisar as suas vítimas. A paz só pode existir com justiça; a paz é fruto da justiça. Por isso falamos de justipaz.

Outra classificação identificada foi a da violência estrutural - e $90 \%$ dos participantes vivem no bairro onde se concentra a população de menor poder aquisitivo e que é considerado o bairro mais violento da cidade, por ser o lócus focal das drogas e prostituição. 
Bairro violento, drogas, muitos adolescentes drogados, prostituição, se não tomar providência a violência só vai aumentando, daqui uns dias não vai poder nem sair na rua depois das $9 \mathrm{~h}$. Você não pode sair com um dinheiro maior, que você sai naquele medo deles pegar, pra você vê, até cinco anos atrás, você ouvia falar de roubo no Rio de Janeiro, hoje, aqui uma cidade tão pequena, você tem que sair com medo, aqui ta se tornando igual ao RJ. E aqui no nosso bairro tem um negócio assim, quando você solta, soltou um foguete lá no alto, todo mundo, já sabe o que é - chegou droga nova, é modo deles falar, então ta igual ao RJ, que lá dizem que é a mesma coisa, eu nunca fui, mas dizem que é a mesma coisa, então aqui ta se tornando um segundo RJ.

Nessa fala percebe-se como o Rio de Janeiro está sendo colocado na mídia como modelo de violência, apesar de São Paulo (capital) ocupar o primeiro lugar no ranking da violência no país.

Na medida em que a literatura aponta o sofrimento da violência como um fator predisponente à reprodução da mesma, objetivou-se questionar a violência vivenciada por esses atores no decorrer de suas vidas, com as seguintes perguntas: "Você já sofreu algum tipo de violência?" "Qual?".

Apesar de as pesquisadoras estarem cientes de que essas violências, muitas vezes veladas, poderiam ser ou não reveladas, a espontaneidade das respostas surpreendeu as pesquisadoras. Uma das entrevistadas respondeu, sem rodeios, sobre a violência sexual sofrida e relatou ter sido "estripada" (estupro) aos nove anos por dois garotos que residiam na mesma rua. Essa mesma funcionária, ao responder à primeira indagação: quando se fala em violência o que lhe vem à cabeça, na sua imaginação?, prontamente diz: "Igual essas pessoas pegar menina novinha, fico com pena delas, menina novinha com menino no braço, não sabe nem cuidar direito." Nota-se a preocupação da entrevistada para que não se repita com as outras o que lhe ocorreu no passado.

Uma delas reporta que "graças a Deus nunca sofri, mas vejo mais na televisão, no jornal".

A violência na mídia, como órgão denunciador, e pelos programas midiáticos violentos tem sido alvo de estudos para apontar seus impactos positivos e/ou negativos, sobretudo para as crianças e adolescentes (Minayo, Njaine, 2003); e a Organização Pan-Americana da Saúde (OPAS/OMS), ciente de que a violência é uma produção histórico-social, enfatiza a necessidade de se aplicarem modelos que contemplem os aspectos socioeconômicos e culturais de cada país.

Outras relataram a violência doméstica praticada pelo cônjuge. Ao serem indagadas se fizeram algumas denúncias, ambas negaram; uma culpou o álcool como uma forma de desculpabilizar o agressor, e a outra se separou. Estudos realizados (Deslandes, Gomes, Silva, 2000; Simão et al., 1997; Soares, Soares e Carneiro, 1996) apontam que, em cerca de 50\% das violências contra a mulher, o marido estava alcoolizado. Quanto ao tema denúncia, somente uma relata que, se houver violência contra sua família: "eu vou reagir como? A gente vai denunciar aquela pessoa que está fazendo aquilo, se acontecer uma violência com a minha família o que eu vou fazer? Não vou resolver com as minhas próprias mãos, eu vou denunciar para policia"; "Maltratar a mulher isso não pode acontecer, marido bater na mulher, espancar os filhos, pois sei de muitos casos em que a mulheres que foram espancadas pelo marido, denunciou e hoje estão presos."

A violência familiar (pai para filho) está tão naturalizada que duas entrevistadas, em um primeiro momento, negaram, e depois perguntaram se as "surras, coças" sofridas quando crianças também seriam consideradas violência. Uma delas afirmou que não conseguiu perdoar o pai e que, até o momento de seu falecimento, os dois permaneceram com as relações cortadas (sem se falar). Esta entrevistada relata ter sofrido maus-tratos não só por parte do pai como dos irmãos. A violência física perpetrada pelos familiares em um passado recente e não recente foi a que provocou lembranças vividas e revividas com emoção e, até mesmo, lágrimas.

Quanto aos homens, $66 \%$ relatam não terem sofrido qualquer tipo de violência, e suas falas são as mesmas: "Graças a Deus, não e espero que nunca aconteça".

Em suas falas, pode-se aferir que sabem que não estão imunes a ela - um sentimento de insegurança que ressentem ao sair de casa.

Um dos homens que relata ter sido vitima da violência chamou a atenção das pesquisadoras, pois o seu relato, por várias vezes, foi manchete dos meios de comunicação: 
A violência do quartel, do exército, a gente passa igual um... Violência assim, na exigência de exercícios, eles passam do limite, vocês tem que fazer tantos exercícios, eles dobram, aquilo não respeitar o seu direito. Manda você fazer trinta abdominais depois noventa, além do limite.

A fala desse homem acometido pela violência nos remete à conceituação da violência em sua origem, do vocábulo latino que vem da palavra "vis", que quer dizer força e se refere às noções de constrangimento e de uso da superioridade física sobre o outro. No seu sentido material, o termo parece neutro, mas quem analisa os eventos violentos descobre que eles se referem a conflitos de autoridades, à luta pelo poder e à vontade de domínio, de posse e de aniquilamento do outro (Minayo, Souza, 2005). Existem manifestações de violência que são aprovadas ou desaprovadas, lícitas ou ilícitas, segundo normas sociais mantidas por usos e costumes naturalizados ou por aparatos legais da sociedade. E essas e tantas outras eram praticadas nos círculos militares contra os novos egressos, e vistas de forma naturalizada e com objetivos legais no exercício da carreira.

A questão sobre a violência contra idosos foi entremeada como uma estratégia de aproximação e inserção das pesquisadoras, e foi verificado que todos os entrevistados, após relatarem suas opiniões sobre violência nos pólos representacional e vivencial, responderam com naturalidade o questionamento: "em sua opinião quais são os tipos de violência que são cometidas contra os idosos?" Foi ressaltado que o questionamento referia-se à violência contra o idoso não apenas institucionalizado, mas também aquele que reside na comunidade.

Dentro da tipologia da violência, o abandono surgiu nos relatos de forma recorrente:

"Maus tratos, deixar ele só tá maltratando ele"; "Abandono"; "O idoso é que nem criança, não sabe o que faz, tem muita gente que bate no idoso. A gente vê muitos aí. Tem pessoa que tem idoso em casa que a família não zela direito, larga pra lá, põe ele dentro de casa, vai e sai pra rua. A família tem que cuidar do idoso. A pessoa deu a vida, tudo por ele, tadinho"; "Muito triste porque é o mesmo que maltratar uma criança porque é indefeso".

As falas quanto ao abandono vêm carregadas de sentimentos de piedade e revolta.

Uma das falas que chamou a atenção das pesquisadoras foi a contradição de uma das entrevistadas, que, num primeiro momento, disse saber sobre a violência por intermédio dos meios de comunicação, mas quando se referiu à violência contra os idosos, sua resposta foi:

No momento não estou lembrando de nenhum tipo de violência contra idoso, não, nunca ouvi. Pode ser que minha mente esteja falhando, uma das colegas que estava próxima perguntou se ela não lembrava do casal de idosos que foi assassinado na roça. Se ela não lembrava? Ela respondeu, viu? Foge da mente da gente... E o casal era conhecido dela.

Este relato chamou a atenção, pois ela já trabalha há 11 anos na Instituição e sua idade é 39 anos; e ao ser relembrado o fato acontecido, sua reação foi de impassibilidade e indiferença.

Outro tipo de violência citado foi a psicológica, que envolve agressões verbais ou gestuais com o objetivo de aterrorizar. "Gritar com eles"; "Bater, gritar com eles"; "À̀s vezes eles vêm com um sorriso falar com a gente e você vai gritar com ele? Coitado. Ele não tem culpa. Se a gente tem nossos problemas... às vezes a gente não está bem... e vai gritar com eles? Isso é uma violência".

Uma das cuidadoras inicia sua fala assim:

Através desse curso que eu fiz de cuidadores de idosos eu descobri que há tanta maneira do idoso sofrer violência que a gente nem imaginava, através de um tom mais alto que gente conversa com ele, através das vezes do paciente pedir assim: o fulano me leva no banheiro e você responder assim, agora, não, eu não posso, eu não tenho tempo, sendo que a gente ta trabalhando na Instituição porque tem o Idoso, porque através, aqui principalmente é que pagam nós se não existisse os idoso aqui não teria emprego pra nós estamos recebendo porque eles são aposentados. 
Esse curso tem trazido, para eles, uma nova ressignificação do processo do envelhecer com dependência, e os conscientizado de que são empregados direto da Instituição, mas que também são empregados indiretos dos idosos, portanto, se não merecedores de respeito pela idade, pelo menos, o respeito ao grau de hierarquia da Instituição, já que eles são copatrões.

O respeito ao idoso que, em muitas culturas, ainda permanece em relação ao acúmulo dos conhecimentos obtidos, mas que, entre outras, com o avanço tecnológico, esse conhecimento está disponível nos meios de comunicação, tornando o idoso obsoleto e, com isso, fazendo-o perder seu espaço de pessoa sábia e multiplicador do conhecimento; conflitos intergeracionais, levando os jovens a um comportamento desrespeitoso, aparecem também nas falas: "Falta de respeito, maltrato; tratar sem dignidade"; "Maltratar com palavras, falta de respeito".

Dentro dos itens dos maus-tratos, foi relembrada a violação aos direitos dos idosos, a violência estrutural que, a todo momento, aparece na mídia, como noticiário: "Idoso apanhando na rua, em filas"; "Até ele andar numa circular, você pode notar que o motorista costuma virar o rosto para o outro lado e finge que não está vendo o idoso, sendo que é direito do idoso, é um tipo de violência".

Ao mesmo tempo, a violência invisibilizada, durante o banho do idoso dependente, foi percebida nas entrevistas: "Pegar ele à força para dar um banho" ; " [...] na hora do banho, que você vê que acontecem muitas coisas mas a gente vai esquecendo[...]". É apontada nestas falas e na literatura como um dos maiores fatores de risco predisponentes às quedas por negligência, maus-tratos ou, mesmo, omissão de assistência a esses idosos (Laks, Werner, Miranda-Sá, 2006; Santos et al., 2006).

Nos relatos acima, o que se percebe é que, embora eles desconheçam as diferentes classificações da violência, eles apontaram quase todas: maus-tratos físicos, psicológicos, negligência, abandono. Os tipos não citados contra os idosos foram: autonegligência, abuso sexual e financeiro.

\section{Conclusão}

Os idosos são alvos fáceis de todos os tipos de violência, por sua fragilidade e dependência, por não saberem a quem recorrer e por não terem um amparo legal ativo, embora exista o Estatuto do Idoso (Lei Federal 10.741/03). Como o idoso institucionalizado pode recorrer a esse instrumento ao seu favor? E aquele que tem um perfil de baixa escolaridade, demência, dependência, sem familiares ou isolado da família e sociedade, cercado por pessoas, muitas vezes, com condições iguais ou piores que a sua? Como procurar os seus direitos? A quem recorrer em sua defesa? Os idosos asilares, pobres, ainda constituem uma população excluída e com dupla invisibilidade para a sociedade.

Os entrevistados, ao se referirem à violência, quase sempre relatavam suas experiências sinceras e profundas como vítimas; porém, quanto aos idosos, era como se a violência sempre acontecesse extramuro, nunca dentro da Instituição, ou, às vezes, percebia-se uma denúncia velada, na penumbra, mas não revelada.

O objeto deste estudo foi analisar as representações sociais de uma equipe multidisciplinar sobre o item violência dentro do escopo do trabalho, aprendizagem e sensibilização nas práticas do cuidar, com o objetivo de minimizar os impactos da violência na saúde dos idosos dessa Instituição. O item violência foi uma das temáticas para o conhecimento das teias e seus imbricamentos no processo do envelhecimento biopsicossocial e legal. A proposta de ação reflexiva possibilitou aos entrevistados uma avaliação do seu trabalho, transformando-os em sujeitos ativos e participativos, discutindo e refletindo sobre suas próprias ações cotidianas frente aos maus-tratos.

Esse é um pequeno passo para um processo de intervenção, que, ao utilizar uma metodologia coparticipativa, a partir do princípio "do e pelo sentido", poderá alcançar resultados de construção mobilizadora e transformadora. 


\section{Colaboradores}

As autoras Alcione Távora Kullok e Ivana de Cássia Baptista dos Santos participaram, igualmente, da elaboração do artigo, de sua discussão e redação e da revisão do texto.

\section{Referências}

ABODERIN, I. Modernisation and ageing theory revisited: current explanations of recent developing world and historical western shifts in material family support for older people. Ageing Soc., v.24, p.29-50, 2004.

ATTIAS-DONFUT, C. Le double circuit des transmissions. In: (Org.). Les solidarités entre générations: vieillesse, familles, état. Paris: Éditions Nathan, 1995.

BORN, T. Carros de boi e instituições de longa permanência para idosos (II). Disponível em: <http://www.portaldoenvelhecimento.net/modos/modos15.htm>. Acesso em: 1 nov. 2007.

BORN, T; BOECHAT, N S A Qualidade do Idoso Institucionalizado. In: FREITAS, E.V.; PY, L.; NERI, A. L.; CANÇADO, F. A. X.C.; GORZONI, M.L.; DOLL, J(Orgs). Tratado de Geriatria e Gerontología. Rio de Janeiro: Guanabara Koogan, 2006.

BRANDÃO, C.R. O afeto da terra. Campinas: Editora da Unicamp, 1999.

CAMARANO, A.A. et al. Transformações no padrão etário da mortalidade brasileira em 1979-1994 e no impacto na força de trabalho. Rio de Janeiro: IPEA, 1997. (Texto para discussão, 512).

CHAIMOWICZ, F.; GRECO, D.B. Dinâmica da institucionalização de idosos em Belo Horizonte, Brasil. Rev. Saude Publica, v.33, n.5, p.454-60, 1999.

DESLANDES, S; GOMES, R; SILVA, C.M.F.P. Caracterização dos casos de violência doméstica contra a mulher atendida em dois hospitais públicos do Rio de Janeiro. Cad. Saude Publica, v.16, n.1, p.129-37, 2000.

FERREIRA, A.B.H. Novo Aurélio Século XXI: o dicionário da língua portuguesa. Rio de Janeiro: Nova Fronteira, 1999.

FREIRE, P. A voz da esposa: a trajetória de Paulo Freire. In: GADOTTI, M. (Org.). Paulo Freire: uma biobibliografia. São Paulo: Cortez/IPF, 1996. p.27-67.

GIL, A.P.M. Redes de solidariedade intergeracional na velhice. Cad. Politica Soc., v.1, p.93-114, 1999.

GUERRA, H.L. et al. A morte de idosos na clínica Santa Genoveva, Rio de Janeiro: um excesso de mortalidade que o sistema público de saúde poderia ter evitado. Cad. Saude Publica, v.16, n.2, p.545-51, 2000.

IBGE - Instituto Brasileiro de Geografia e Estatística. Estimativas de população para $1^{\circ}$ de julho de 2004. Disponível em: <http://www.ibge.gov.br>. Acesso em: 27 jun. 2005.

KEMP, C.L.; DENTON, M. The allocation of responsibility for later life: canadian reflections on the roles of individuals, government, employers and families. Ageing Soc., v.23, p.737-60, 2003.

KOSBERG, J.I. Preventing elder abuse: identification of high risk factors prior to placement decisions. Gerontologist, v.28, p.43-50, 1988. 
KULLOK, A.T. et al. Idosos institucionalizados e úlcera de pressão: excesso de preocupação ou risco iminente? In: CONGRESSO BRASILEIRO DE GERIATRIA E GERONTOLOGIA, 15., 2006, Goiânia. Anais ... Goiânia, 2006. p.190.

LAKS, J.; WERNER; L.; MIRANDA-SÁ JR., L.S. Psiquiatria forense e direitos humanos nos pólos da vida: crianças, adolescentes e idosos. Rev. Bras. Psiquiatr, v.28, supl.2, p80-5, 2006.

LANE, S.T.M.; SAWAIA, B.B. Dimensão ético-afetiva do adoecer da classe trabalhadora. In: ___ (Orgs). Novas veredas da psicologia social. São Paulo: Brasiliense, 1995. p.73-84.

LEMOS, N.; MEDEIROS, S.L. Suporte social ao idoso dependente. In: FREITAS, E.V. et al. (Orgs). Tratado de geriatria e gerontologia. Rio de Janeiro: Guanabara Koogan, 2006. p.1227-33.

MACHADO, L.; QUEIRÓZ, Z.V. Negligência e maus tratos. In: FREITAS, E.V. et al. (Orgs). Tratado de geriatria e gerontologia. Rio de Janeiro: Guanabara Koogan, 2006. p.1152-9.

MICHAELIS: Moderno dicionário da língua portuguesa. São Paulo: Melhoramentos, 1998.

MINAYO, M.C.S.; ASSIS, S.G.; SOUZA, E.R. (Orgs.). Avaliação por triangulação de métodos: abordagem de programas sociais. Rio de Janeiro: Fiocruz, 2005.

MINAYO, M.C.S.; NJAINE, K.Violência na escola: identificando pistas para a prevenção. Interface - Comunic., Saúde, Educ., v.7, n.13, p.119-34, 2003.

MINAYO, M.C.S.; SOUZA, E.R. Violência contra idosos: é possível prevenir. In: SOUZA, E.R.; MINAYO, M.C.S. (Orgs.). Impacto da violência na saúde dos brasileiros:

violência um problema para saúde dos brasileiros. Brasília: Ministério da Saúde, 2005. p.141-65.

MORAES, R. Análise de conteúdo: limites e possibilidades. In: ENGERS, M.E. (Org). Paradigmas e metodologias de pesquisa em educação. Porto Alegre: EDIPUCRS; 1994. p.103-11.

OMS. Organização Mundial de Saúde. WHO/INPEA. Missing voices: views of older persons on elder abuse. Geneva, 2002.

OPAS. La violencia en las Americas: la pandemia social del siglo XX. Washington, DC: OPAS, 1996.

PAPALEO NETO, M.O. Estudo da velhice: histórico, definição do campo e termos básicos. In: FREITAS, E.V. et al. (Orgs). Tratado de geriatria e gerontologia. Rio de Janeiro: Guanabara Koogan, 2006. p.2-12.

RATHBONE-MCCUAN, E.; VOYLES, B. Case detection of abused elderly parents. Am. J. Psychiatry, v.139, p.189-92, 1982.

SANTOS, I.C.B. et al. Estudo transversal sobre os fatores predisponentes à hospitalização de idosos devido a quedas e seu impacto financeiro no setor de saúde no Município de Caratinga/ MG. In: CONGRESSO BRASILEIRO DE GERIATRIA E GERONTOLOGIA, 15., 2006, Goiânia. Anais ... Goiânia, 2006. p.188.

SAWAIA, B.B. (Org.). Novas veredas da psicologia social. São Paulo: Brasiliense, 1995.

SIQUEIRA, M.E.C. Longa permanência: mudanças no ambiente, em práticas e atitudes. Disponível em: <http://www.portaldoenvelhecimento.net/acervo/pforum/ ilpis2.htm >. Acesso em: 2 nov. 2007.

SIMÃO, M.O. et al. Alcoolismo feminino: revisão de aspectos relacionados à violência. Rev. ABP-APAL, n.19, p.139-48, 1997. 
SOARES, L.E.; SOARES, B.M.; CARNEIRO, L.P. Violência contra a mulher: as DEAMs e os pactos domésticos. In: SOARES, L.E. (Org.). Violência e política no Rio de Janeiro. Rio de Janeiro: Relume-Dumará/ISER, 1996. p.65-106.

SPINK, M.J.P. O conceito de representação social na abordagem psicossocial. Cad. Saude Publica, v.9, n.3, p.300-8, 1993.

STRECK, D.R. Paulo Freire: ética, utopia e educação. Petrópolis: Vozes, 1999. 
O Brasil está passando por um processo de envelhecimento populacional rápido e intenso, estimando-se que $1 \%$ dos idosos brasileiros esteja institucionalizado. Apesar dos avanços investigativos na área da geriatria e gerontologia da última década, os estudos acerca das Instituições de longa permanência no país ainda são incipientes, deparando-se com sérios problemas relacionados à qualidade do cuidado. Neste artigo, de abordagem qualitativa e cunho exploratório-descritivo, foram investigadas as representações sociais de funcionários sobre violência em uma instituição de longa permanência de um município de Minas Gerais. Os dados, oriundos da transcrição das entrevistas, foram processados por meio de análise de conteúdo. Os entrevistados referiram-se à violência e relataram suas experiências sinceras e profundas como vitimas, porém, quanto aos idosos, era como se a violência sempre acontecesse extramuro, nunca dentro da Instituição, percebendo-se, às vezes, uma denúncia velada, mas não revelada.

Palavras-chave: Envelhecimento. Instituição de longa permanência para idosos. Violência. Representação social.

The social representations of employees of a long-stay institution in the interior of Minas Gerais regarding violence

Brazil is going through a fast and intense process of population aging. It is estimated that $1 \%$ of elderly Brazilians are institutionalized. Despite investigative advances within the field of geriatrics and gerontology over the last decade, studies on long-stay institutions in this country are at an incipient stage and serious problems relating to quality of care are appearing. Through a qualitative, exploratory and descriptive approach, this paper investigates the social representations of employees of a longstay institution in a municipality in the State of Minas Gerais, regarding violence at that institution. The data, from the interview transcript, were processed using content analysis. The interviewees made mention of violence and told of their sincere and deep experiences as victims. However, with regard to the elderly people, it was as if the violence always happened outside the walls, i.e. never inside the institution. Sometimes a veiled but undisclosed complaint was perceived.

Key words: Aging. Homes for the aged. Violence. Social representation.

\section{Las representaciones sociales de funcionarios de una institución de larga permanencia sobre violencia en el interior del estado brasileño de Minas Gerais}

Brasil está pasando por un proceso de envejecimiento de la población rápido e intenso, estimándose que el $1 \%$ de los ancianos brasileños está institucionalizado. A pesar de los avances investigativos en el área de geriatría y gerontología de la última década, los estudios sobre las instituciones de larga permanencia en el país son aún incipientes, afrontando serios problemas relacionados con la calidad del cuidado. En este artículo, de aproximación cualitativa y cuño exploratorio-descriptivo, se investigan las representaciones sociales de funcionarios sobre violencia en una institución de larga permanencia de un municipio de Minas Gerais. Los datos, oriundos de la transcripción de las entrevistas, se han procesado por medio de análisis de contenido. Los entrevistados se refieren a la violencia y relatan sus experiencias sinceras y profundas como víctimas. Sin embargo, en relación a los ancianos es como si la violencia siempre sucediera extra-muro, nunca dentro de la institución, percibiéndose a veces una denuncia velada aunque no revelada.

Palabras clave: Envejecimiento. Hogares para ancianos. Violencia. Representación social. 